\title{
Roles of $\alpha_{2}$-adrenoceptors and glutamate mechanisms in the external urethral sphincter continence reflex in rats
}

\author{
Akira Furuta, Koji Asano, Shin Egawa, William C. de Groat, Michael B. Chancellor, and Naoki \\ Yoshimura \\ Department of Urology, Jikei University School of Medicine, Tokyo, JAPAN \\ Department of Urology, University of Pittsburgh School of Medicine, Pittsburgh, Pennsylvania, USA \\ Department of Pharmacology, University of Pittsburgh School of Medicine, Pittsburgh, \\ Pennsylvania, USA
}

William Beaumont Hospital, Royal Oak, Michigan, USA

\begin{abstract}
Purpose-To investigate the role of $\alpha_{2}$-adrenoceptors (ARs) and glutamate mechanisms of the urethral continence reflex in response to abdominal pressure increases.

Materials and Methods-Under urethane anesthesia, external urethral sphincter (EUS)electromyogram activity was evaluated in spinal cord transected (T8-9) female rats during lower abdominal wall compression before and after intravenous (i.v.) application of test drugs. The effects of MK-801 (0.03, 0.3 and $3 \mathrm{mg} / \mathrm{kg}$ i.v.), an N-methyl-D-aspartate glutamate receptor antagonist, or medetomidine (0.03, 0.3 and $3 \mathrm{mg} / \mathrm{kg}$ i.v.), an $\alpha_{2}$-AR agonist, on EUS activity were examined. Then, idazoxan $(0.3 \mathrm{mg} / \mathrm{kg}$ i.v. $)$, an $\alpha_{2}$-AR antagonist, was administered before or after application of MK-801 (1 mg/kg i.v.). In addition, idazoxan $(0.3 \mathrm{mg} / \mathrm{kg}$ i.v. $)$ was administered following application of duloxetine (1 mg/kg, i.v.), a serotonin/norepinephrine reuptake inhibitor.
\end{abstract}

Results-Both MK-801 and medetomidine dose-dependently decreased the EUS activity. Idazoxan significantly increased the EUS activity by $64 \%$, but the increase in EUS activity after idazoxan was abolished by MK-801. On the other hand, idazoxan did not reverse the inhibitory effects of MK-801. In addition, idazoxan significantly potentiated the duloxetine effects on the EUS activity by $120 \%$.

Conclusions-These results indicate that: 1) glutamate is a major excitatory neurotransmitter in the urethral continence reflex response to abdominal pressure increases, 2) $\alpha_{2}$-AR activation suppresses EUS activity probably via presynaptic inhibition of glutamate release and 3) the effects of serotonin/norepinephrine reuptake inhibitors are enhanced by $\alpha_{2}$-AR inhibition. Therefore, $\alpha_{2}$-AR antagonists could be beneficial for the treatment of stress urinary incontinence.

\section{Keywords}

$\alpha_{2}$-adrenoceptor; glutamate; urinary incontinence; urethral continence reflex; external urethral sphincter

Correspondence to: Akira Furuta, M.D., Department of Urology, Jikei University School of Medicine, 3-25-8 Nishishinbashi, Minatoku, Tokyo, JAPAN, 105-8461, Phone: 81-3-3433-1111, Fax: 81-3-3437-2389, E-mail: a-furuta@ rf7.so-net.ne.jp. 


\section{Introduction}

There are more than 200 million people worldwide with urinary incontinence, a condition that is associated with a significant social impact and a reduced quality of life. ${ }^{1}$ The transvaginal tape procedure has recently gained popularity for the treatment of stress urinary incontinence (SUI) because of its relatively simple techniques and high success rates. On the other hand, there are few drugs that can enhance urinary continence under stress conditions such as sneezing, coughing or lifting heavy objects because pharmacological targets for improving urethral closure mechanisms under stress conditions are not fully elucidated. We previously reported that active urethral closure during sneezing is induced by direct activation of pudendal nerves and somatic nerves innervating pelvic floor muscles, ${ }^{2}$ and that active urethral closure induced in Valsalva-like stress conditions is mediated by pelvic-to-hypogastric and pelvic-topudendal reflex pathways. ${ }^{3}$

$\alpha$-adrenoceptor (AR) agonists showed modest improvement when used for the treatment of SUI but these drugs have not been commonly used because of the risk of hypertension and/or hemorrhagic stroke. ${ }^{4}$ Imipramine and duloxetine have been used clinically to treat SUI; however duloxetine, although available in Europe, has not been approved by the United States Food and Drug Administration. These drugs are thought to act by inhibiting reuptake of serotonin (5-hydroxytryptamine [5-HT]) and norepinephrine (NE) in the Onuf's nucleus, leading to stimulation of 5-HT and NE receptors, which increases external urethral sphincter (EUS) activity. ${ }^{5-8}$ We have recently reported that 5 -HT and NE pathways are important in maintaining sneeze-induced urethral continence reflexes and that duloxetine-induced enhancement of the reflexes is predominantly mediated by $\alpha_{1}$-ARs in the spinal cord. ${ }^{9}$

Previous studies that examined the pelvic-to-pudendal spinal reflex during urine storage ${ }^{10}$, 11 have demonstrated that the pelvic nerve electrical stimulation or bladder distension induced by saline infusion can induce an increase in EUS activity, which is attenuated by intrathecal or intravenous (i.v.) administration of N-methyl-D-aspartate (NMDA) glutamate receptor antagonists. Glutamate is well known as an excitatory neurotransmitter in the central nervous system, and its release at nerve terminals is regulated by presynaptic $\alpha_{2}$-ARs in the dorsal horn 12 or at synapses on sympathetic preganglionic neurons. ${ }^{13}$ However, the involvement of glutamate and $\alpha_{2}$-AR systems in the control of urethral closure reflexes induced in stress conditions remains to be explored.

Therefore, this study was undertaken: 1) to develop a reproducible animal model to investigate EUS activity during urethral continence reflexes induced in Valsava-like stress conditions and 2 ) to clarify whether EUS responses in stress conditions are controlled by glutamate and/or $\alpha_{2}$-AR mechanisms.

\section{Material and Methods}

\section{Animal preparation}

The spinal cord of 20 female Sprague-Dawley rats, weighing 250-280 g, was transected under isoflurane anesthesia at the T8-9 level to eliminate voiding reflexes induced by spino-bulbospinal reflex pathways. The bladder neck was ligated with 4-0 silk threads through a middle abdominal incision to prevent urinary leakage when the lower abdominal wall was manually compressed. A polyethylene (PE)-90 catheter was inserted through the bladder dome into the bladder to monitor intravesical pressures, and PE-50 and PE-10 catheters were implanted into the carotid artery and jugular vein to monitor blood pressure and to administer test drugs, respectively. After the surgery, the abdominal wall was tightly closed, and then isoflurane anesthesia was replaced with urethane anesthesia (1.2 g/kg subcutaneously) to examine EUSelectromyogram activity. All experiments were conducted in accordance with institutional 
guidelines and approved by the University of Pittsburgh Institutional Animal Care and Use Committee.

\section{External urethral sphincter electromyogram recording}

Two epoxy-coated copper wire electromyogram electrodes (50 $\mu \mathrm{m}$, M.T. Giken, Tokyo, Japan) were inserted transperineally $1 \mathrm{~mm}$ lateral to the middle urethra for EUS-electromyogram recording. The EUS-electromyogram activity was amplified 20,000-fold and filtered (high and low-frequency cut-off at $3,000 \mathrm{~Hz}$ and $30 \mathrm{~Hz}$, respectively) by a preamplifier (Grass P511AC, Cleveland, OH, USA) and then recorded using a data-acquisition software (sampling at 4000 $\mathrm{Hz}$, Chart, ADInstruments, Castle Hill NSW, Australia) on a computer system equipped with an analog-to-digital converter (PowerLab, ADInstruments). Under urethane anesthesia, the bladder was filled with $0.3 \mathrm{ml}$ of saline solution because more than $0.5 \mathrm{ml}$ of saline infusion sometimes induced spontaneous bladder contractions. ${ }^{14}$ The spikes of EUS-electromyogram during lower abdominal wall compression for 10 seconds were recorded three times at 2-minute intervals before and after drug application to examine the effects of test drugs on EUS activity. The level of bladder compression was monitored through the intravesical catheter to produce similar compression patterns of intravesical pressure rises (approximately $90 \mathrm{cmH}_{2} \mathrm{O}$ in amplitude) among trials. At the end of experiments, the trachea was cannulated with PE-200 tubing, and $\alpha$-bungarotoxin (Sigma, St. Louis, MO, USA, $0.4 \mathrm{mg} / \mathrm{kg}$ i.v.), a neuromuscular blocking agent, was administered during artificial ventilation to confirm that the electrode was recording striated muscle activity and to determine the level of electrical noise. EUSelectromyogram activity exceeding the electrical noise level was rectified and measured by integration of the area under the curve using Chart software. The average area of EUSelectromyogram during bladder compression at three times was taken as EUS activity for each animal (Fig. 1).

\section{Application of drugs}

Cumulative doses of MK-801, an NMDA glutamate receptor antagonist (0.03, 0.3 and $3 \mathrm{mg} /$ $\mathrm{kg}$ i.v., Sigma) or medetomidine, an $\alpha_{2}$-AR agonist $(0.03,0.3$ and $3 \mathrm{mg} / \mathrm{kg}$ i.v., Tocris Cookson, Ellisville, MO, USA) were administered at 10-minute intervals to examine the involvement of NMDA glutamatergic receptors and $\alpha_{2}$-ARs in the control of EUS activity ( $\mathrm{n}=4$ per each drug). Idazoxan, an $\alpha_{2}$-AR antagonist, $(0.3 \mathrm{mg} / \mathrm{kg}$ i.v., Sigma) was administered before or after administration of MK-801 (1 mg/kg i.v.) at 10-minute intervals to investigate the relationship between $\alpha_{2}$-AR and NMDA receptor activation ( $\mathrm{n}=4$ each before or after MK-801). In addition, idazoxan $(0.3 \mathrm{mg} / \mathrm{kg}$ i.v.) was administered after duloxetine, a 5-HT/NE reuptake inhibitor (1 $\mathrm{mg} / \mathrm{kg}$ i.v., Kemprotec, Middlesbrough, UK) at a 10-minute interval to determine whether $\alpha_{2}-$ AR antagonists can augment the effect of duloxetine on EUS activity $(n=4)$. All test drugs were dissolved in saline solution and administered i.v. in $0.5 \mathrm{ml} / \mathrm{kg}$ volume followed by a flush of $0.1 \mathrm{ml}$ saline solution.

\section{Data Analysis}

All data are represented as mean values \pm standard error of the mean. Statistical analysis software (Prism, Graphpad Software, San Diego, CA, USA) was used to compare the results. Repeated measures ANOVA, followed by Turkey's multiple comparison test, was used to compare changes in the EUS activity before and after cumulative injections of MK-801 and medetomidine. Changes in the EUS activity before and after single dose treatments of duloxetine, idazozan and/or MK-801 were analyzed using paired Student $t$-test. $\mathrm{P}<0.05$ was regarded as statistically significant. 


\section{Results}

The mean intravesical pressure from all experiments during abdominal compression was 95.6 $\pm 5.0 \mathrm{cmH}_{2} \mathrm{O}$, and was not different among subgroups that received different drug injections. As shown in Fig. 1, abdominal compression induced increases in EUS-electromyogram activity, which was abolished by $\alpha$-bungarotoxin, a neuromuscular blocking agent. In addition, we often observed after-discharges of EUS-electromyogram following cessation of abdominal compression, which were usually most obvious after the first compression (Fig. 1). Cumulative administration of MK-801 (0.03, 0.3 and $3 \mathrm{mg} / \mathrm{kg}$ i.v. $)$ showed that the lowest dose $(0.03 \mathrm{mg} /$ $\mathrm{kg}$ ) of MK-801 did not change the EUS activity. However, higher single doses $(0.3$ and $3 \mathrm{mg} /$ $\mathrm{kg})$ of MK-801 significantly decreased the EUS activity by $70 \%(\mathrm{P}<0.05)$ and $91 \%(\mathrm{P}<0.01)$, respectively, compared with the pre-drug control value (Fig. 2A). In addition, the highest cumulative dose $(3 \mathrm{mg} / \mathrm{kg})$ of MK-801 significantly decreased the mean blood pressure compared with control $(\mathrm{P}<0.01)$, but lower single doses $(0.03$ and $0.3 \mathrm{mg} / \mathrm{kg})$ of MK-801 did not change the mean blood pressure (Fig. 2B).

Cumulative administration of medetomidine ( $0.03,0.3$ and $3 \mathrm{mg} / \mathrm{kg}$ i.v.) significantly decreased the EUS activity by $27 \%(\mathrm{P}<0.05), 54 \%(\mathrm{P}<0.01)$ and $82 \%(\mathrm{P}<0.01)$, respectively, compared with control (Fig.1 and Fig. 3A). On the other hand, cumulative administration of medetomidine did not change the mean blood pressure (Fig 3B), but higher single doses $(0.3$ and $3 \mathrm{mg} / \mathrm{kg}$ ) of medetomidine caused a biphasic blood pressure response; blood pressure fell after a transient hypertensive phase (data not shown).

Administration of idazoxan ( $0.3 \mathrm{mg} / \mathrm{kg}$ i.v.) significantly increased the EUS activity by $64 \%$ compared with control $(\mathrm{P}<0.05)$, and subsequent application of MK-801 $(1 \mathrm{mg} / \mathrm{kg}$ i.v. $)$ decreased the EUS activity to $33 \%$ of the control value $(\mathrm{P}<0.05)$ (Fig. 4A). When the sequence of drug administration was reversed, administration of MK-801 significantly decreased the EUS activity by $74 \%(\mathrm{P}<0.01)$, and subsequent application of idazoxan did not further change the EUS activity (Fig. 4B). Idazoxan did not change the mean blood pressure (idazoxan: 133.3 $\pm 4.2 \mathrm{cmH}_{2} \mathrm{O}$ versus control: $140.0 \pm 2.6 \mathrm{cmH}_{2} \mathrm{O}$ ).

Administration of duloxetine ( $1 \mathrm{mg} / \mathrm{kg}$ i.v) significantly increased the EUS activity by $45 \%$ $(\mathrm{P}<0.05)$. The increased EUS activity by duloxetine was significantly increased by subsequent application of idazoxan $(0.3 \mathrm{mg} / \mathrm{kg}$ i.v. $)$ by $52 \%$ compared with duloxetine alone $(\mathrm{P}<0.05)$ or by $120 \%$ compared with pre-duloxetine control $(\mathrm{P}<0.01)$ (Fig. 5A). Consecutive i.v. administration of duloxetine and idazoxan did not change the mean blood pressure (duloxetine: $159.0 \pm 3.8 \mathrm{cmH}_{2} \mathrm{O}$ versus idazoxan: $151.8 \pm 4.6 \mathrm{cmH}_{2} \mathrm{O}$ versus control: $152.0 \pm 5.0 \mathrm{cmH}_{2} \mathrm{O}$ ) (Fig. 5B).

\section{Discussion}

In this study, we used rats with acute spinal cord transection, in which voiding induced by supraspinal micturition reflex pathways was suppressed while urethral reflexes induced by bladder distension or compression, which are predominantly organized by lumbosacral spinal reflex pathway, were kept intact. ${ }^{15,16}$ We have also previously reported that EUS contractions during passive intravesical pressure rises mediated by pelvic-to-pudendal reflex pathways contribute to urinary continence because transection of pelvic and pudendal nerves significantly reduced leak point pressure in this animal model. ${ }^{3}$ This study further demonstrated that measuring EUS-electromyogram is a useful method for quantitative analysis of EUS activity in Valsalva-like stress conditions induced by abdominal compression. In addition, since the level of intravesical pressure increases $\left(95.6 \mathrm{cmH}_{2} \mathrm{O}\right)$ during abdominal compression was higher compared with abdominal leak point pressure $\left(50 \mathrm{cmH}_{2} \mathrm{O}\right)$ previously 
reported in rats, ${ }^{17}$ it is possible that the EMG responses recorded in this study might be exaggerated.

Cumulative administration of MK-801 dose-dependently decreased EUS activity during abdominal compression by up to $91 \%$ and had no effect on blood pressure except for the highest dose $(3 \mathrm{mg} / \mathrm{kg})$, suggesting that the effect of MK-801 on EUS activity is not induced directly by changes in cardiovascular function. Glutamate is known to be the major neurotransmitter controlling lower urinary tract function in central nervous system, ${ }^{18}$ and the inhibitory effects of MK-801 in the spinal cord on EUS activity increased during stimulation of the pelvic nerve have been reported in rats. ${ }^{10,11}$ Thus, the pelvic-to-pudendal urethral continence reflex induced in Valsalva-like stress conditions is also likely to be dependent upon activation of glutamatergic NMDA receptors in the spinal cord. However, because the experiments in this study were performed in urethane-anesthetized animals, the possibility that anesthesia might have affected the results cannot be excluded. In addition, we observed a variation in the control (predrug) EMG activity during abdominal compression among animals (Figs. 2-5), which is possibly due to the difference in the depth of anesthesia.

We also found that administration of medetomidine, an $\alpha_{2}$-AR receptor agonist, dosedependently decreased EUS activity during abdominal compression by $82 \%$ while inhibition of $\alpha_{2}$-ARs by idazoxan conversely increased EUS activity by $64 \%$ without affecting blood pressure. These results indicate that $\alpha_{2}$-ARs are activated to suppress the spinal urethral continence reflex that increases EUS activity during abdominal pressure increases. Thus, we further examined the relationship between $\alpha_{2}$-ARs and glutamatergic mechanisms in the control of the urethral continence reflex. Administration of idazoxan increased EUS activity by $64 \%$, and the idazoxan-induced increase in EUS activity was abolished by subsequent application of MK-801. However, administration of idazoxan following MK-801 did not increase EUS activity, which was decreased by MK-801. These results suggest that the $\alpha_{2}$-ARmediated inhibitory effect may be mediated by suppression of glutamatergic mechanisms. Previous studies have shown that the release of glutamate is regulated by $\alpha_{2}$-ARs presynaptically in the dorsal horn 12 and at synapses on sympathetic preganglionic neurons. 13 Thus it seems reasonable to assume that $\alpha_{2}$-ARs also regulate the release of glutamate in the spinal cord to modulate the pelvic-to-pudendal spinal reflex induced in Valsalva-like stress conditions (Fig. 6). Therefore, the use of $\alpha_{2}$-AR antagonists, which increase EUS activity during abdominal pressure increases, could be an alternative modality for the treatment of SUI.

Duloxetine, a 5-HT and NE reuptake inhibitor, has demonstrated clinical efficacy in the treatment of SUI. ${ }^{19}$ The action of this drug is considered to be associated with reuptake inhibition of 5-HT and NE at Onuf's nucleus of the sacral spinal cord. 7,20 In the present study, following duloxetine application, idazoxan dramatically increased EUS activity by $52 \%$ compared with duloxetine alone or by $120 \%$ compared with pre-duloxetine control, which was similar to the combined effects of idazoxan (64\%) and duloxetine (45\%) administered separately. These results indicate that duloxetine, which increases NE concentrations at noradrenergic nerve terminals in the spinal cord, activates $\alpha_{2}$-ARs to counteract the stimulatory effects of duloxetine on the urethral continence reflex. Danuser et al. ${ }^{5}$ previously demonstrated that modulation of somatic reflex pathways to the lower urinary tract by NE reuptake inhibition caused activation of not only facilitatory $\alpha_{1}$-ARs, but also inhibitory $\alpha_{2}$-ARs in the spinal cord using cats. We recently reported that the enhancing effects of duloxetine on the urethral continence reflex during sneezing were mainly mediated by activation of $\alpha_{1}$-ARs in the spinal cord and that $\alpha_{2}$-AR-mediated inhibition by duloxetine was also observed when both $\alpha_{1}$-ARs and 5-HT receptors were suppressed in rats. ${ }^{9}$ Taken together, it is assumed that duloxetine can induce activation of facilitatory $\alpha_{1}$-ARs as well as inhibitory $\alpha_{2}$-ARs in the spinal cord to modulate the urethral continence reflex induced in Valsalva-like stress conditions. Therefore, 
combined applications of 5-HT/NE reuptake inhibitors and $\alpha_{2}$-AR antagonists could be more effective for the treatment of SUI than the single drug therapy (Fig. 6).

\section{Conclusions}

The present study suggests that glutamate is the major excitatory neurotransmitter in the pelvicto-pudendal spinal reflex induced in Valsalva-like stress conditions. Since $\alpha_{2}$-ARs inhibit the release of glutamate in the spinal cord, $\alpha_{2}$-AR antagonists could be useful as an alternative treatment of SUI. In addition, $\alpha_{2}$-AR antagonists could enhance the therapeutic effects of 5HT/NE reuptake inhibitors by blocking the inhibitory effects of duloxetine mediated via $\alpha_{2-}$ AR activation.

\section{Acknowledgements}

This study was supported by grants from National Institutes of Health: DK067226, AR049398 and DK055387.

\section{Abbreviations and Acronyms}

SUI, stress urinary incontinence; EUS, external urethral sphincter; NMDA, N-methyl-Daspartate; AR, adrenoceptor; 5-HT, 5-hydroxytryptamine; NE, norepinephrine.

\section{References}

1. Norton P, Brubaker L. Urinary incontinence in women. Lancet 2006;367:57. [PubMed: 16399154]

2. Kamo I, Kaiho Y, Canon TW, Chancellor MB, de Groat WC, Prantil RL, et al. Functional analysis of active urethral closure mechanisms under sneeze induced stress condition in a rat model of birth trauma. J Urol 2006;176:2711. [PubMed: 17085201]

3. Kamo I, Cannon TW, Conway DA, Torimoto K, Chancellor MB, de Groat WC, et al. The role of bladder-to-urethral reflexes in urinary continence mechanisms in rats. Am J Physiol Renal Physiol 2004;287:F434. [PubMed: 15113743]

4. Kernan WN, Viscoli CM, Brass LM, Broderick JP, Brott T, Feldmann E, et al. Phenylpropanolamine and the risk of hemorrhagic stroke. N Engl J Med 2000;343:1826. [PubMed: 11117973]

5. Danuser H, Bemis K, Thor KB. Pharmacological analysis of the noradrenergic control of central sympathetic and somatic reflexes controlling the lower urinary tract in the anesthetized cat. J Pharmacol Exp Ther 1995;274:820. [PubMed: 7636745]

6. Danuser H, Thor KB. Spinal 5-HT2 receptor-mediated facilitation of pudendal nerve reflexes in the anaesthetized cat. Br J Pharmacol 1996;118:150. [PubMed: 8733588]

7. Thor KB, Katofiasc MA. Effects of duloxetine, a combined serotonin and norepinephrine reuptake inhibitor, on central neural control of lower urinary tract function in the chloralose-anesthetized female cat. J Pharmacol Exp Ther 1995;274:1014. [PubMed: 7636716]

8. Kaiho Y, Kamo I, Chancellor MB, Arai Y, de Groat WC, Yoshimura N. Role of noradrenergic pathways in sneeze-induced urethral continence reflex in rats. Am J Physiol Renal Physiol 2007;292:F639. [PubMed: 17047168]

9. Miyazato M, Kaiho Y, Kamo I, Chancellor MB, Sugaya K, de Groat WC, et al. Effect of Duloxetine, a Norepinephrine and Serotonin Reuptake Inhibitor, in Sneeze-induced Urethral Continence Reflex in Rats. Am J Physiol Renal Physiol. 2008in press

10. Chang HY, Cheng CL, Chen JJ, de Groat WC. Roles of glutamatergic and serotonergic mechanisms in reflex control of the external urethral sphincter in urethane-anesthetized female rats. Am J Physiol Regul Integr Comp Physiol 2006;291:R224. [PubMed: 16469836]

11. Liao JM, Huang PC, Pan SF, Chen MJ, Tung KC, Peng HY, et al. Spinal glutamatergic NMDAdependent pelvic nerve-to-external urethra sphincter reflex potentiation caused by a mechanical stimulation in anesthetized rats. Am J Physiol Renal Physiol 2007;292:F1791. [PubMed: 17287199] 
12. Kawasaki Y, Kumamoto E, Furue H, Yoshimura M. Alpha 2 adrenoceptor-mediated presynaptic inhibition of primary afferent glutamatergic transmission in rat substantia gelatinosa neurons. Anesthesiology 2003;98:682. [PubMed: 12606912]

13. Miyazaki T, Kobayashi H, Tosaka T. Presynaptic inhibition by noradrenaline of the EPSC evoked in neonatal rat sympathetic preganglionic neurons. Brain Res 1998;790:170. [PubMed: 9593880]

14. Flood HD, Liu JL, Fraser MO, de Groat WC. Sex differences in the nitric oxide (NO) mediated smooth muscle component and striated muscle component of urethral relaxation in rats. Neurourol Urodyn 1995;14:517.

15. de Groat WC. Anatomy of the central neural pathways controlling the lower urinary tract. Eur Urol 1998;34:2. [PubMed: 9705544]

16. Kakizaki H, Fraser MO, De Groat WC. Reflex pathways controlling urethral striated and smooth muscle function in the male rat. Am J Physiol 1997;272:R1647. [PubMed: 9176360]

17. Jung SY, Fraser MO, Ozawa H, Yokoyama O, Yoshiyama M, De Groat WC, et al. Urethral afferent nerve activity affects the micturition reflex; implication for the relationship between stress incontinence and detrusor instability. J Urol 1999;162:204. [PubMed: 10379788]

18. Yoshiyama M, Nezu FM, Yokoyama O, Chancellor MB, de Groat WC. Influence of glutamate receptor antagonists on micturition in rats with spinal cord injury. Exp Neurol 1999;159:250. [PubMed: 10486193]

19. Ghoniem GM, Van Leeuwen JS, Elser DM, Freeman RM, Zhao YD, Yalcin I, et al. A randomized controlled trial of duloxetine alone, pelvic floor muscle training alone, combined treatment and no active treatment in women with stress urinary incontinence. J Urol 2005;173:1647. [PubMed: 15821528]

20. Thor KB. Targeting serotonin and norepinephrine receptors in stress urinary incontinence. Int $\mathbf{J}$ Gynaecol Obstet 2004;86(Suppl 1):S38. [PubMed: 15302566] 


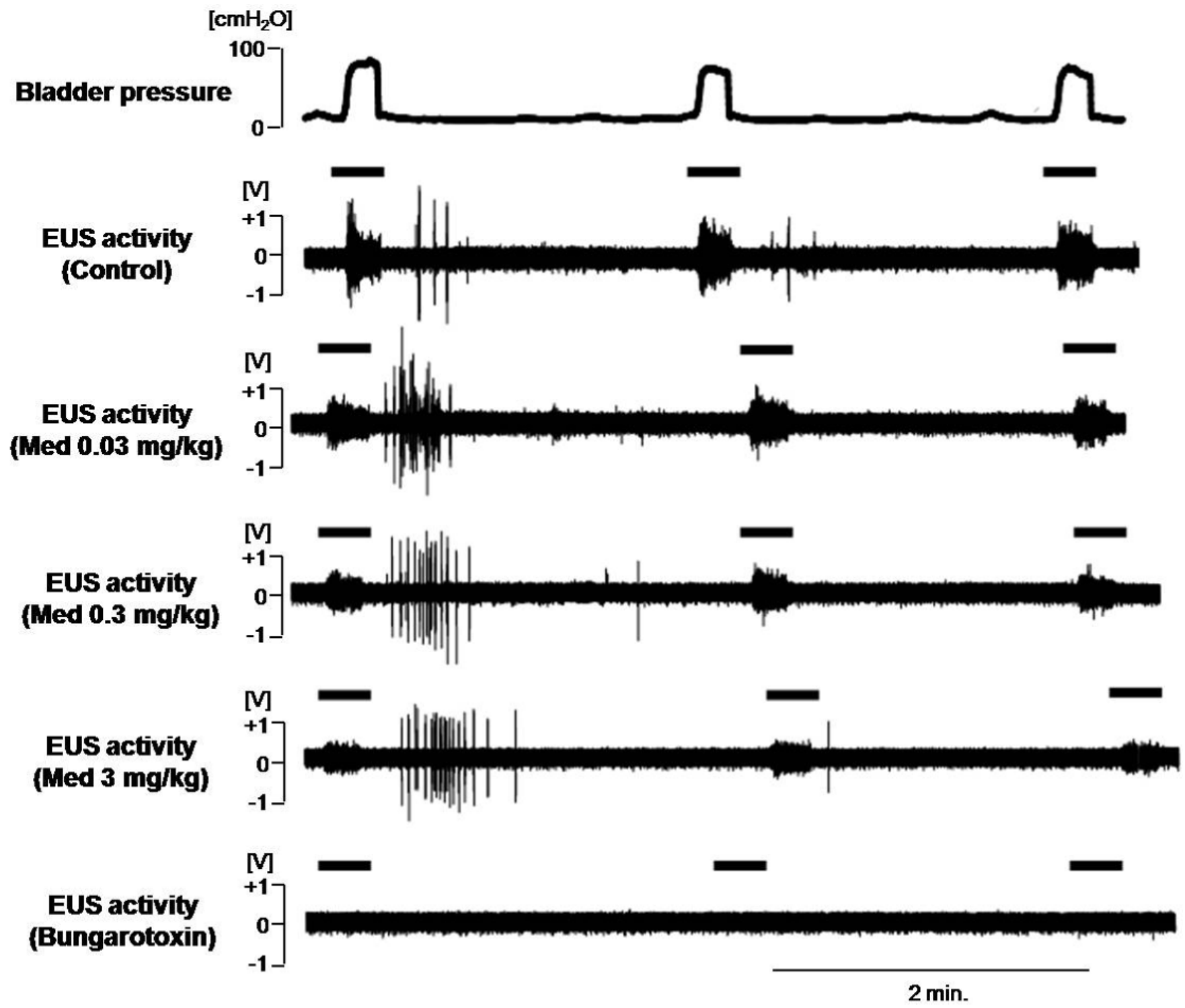

FIGURE 1.

Representative traces of intravescial pressures and EUS-electromyogram. EUS activity during lower abdominal wall compression for 10 seconds (bar) was recorded three times at 2 minute intervals before (control) and 10 min after i.v. administration of test drugs. Abdominal compression induced increases in EUS-electromyogram activity, and cumulative application of medetomidine (Med; 0.03, 0.3 and $3 \mathrm{mg} / \mathrm{kg}$ ) dose-dependently decreased the EUS activity during abdominal compression. In addition, after-discharges of EUS-electromyogram were often observed following cessation of abdominal compression, most obviously after the first compression. EUS activity was completely eliminated by $\alpha$-bungarotoxin $(0.4 \mathrm{mg} / \mathrm{kg})$ at the end of experiment (lowest trace). 
A

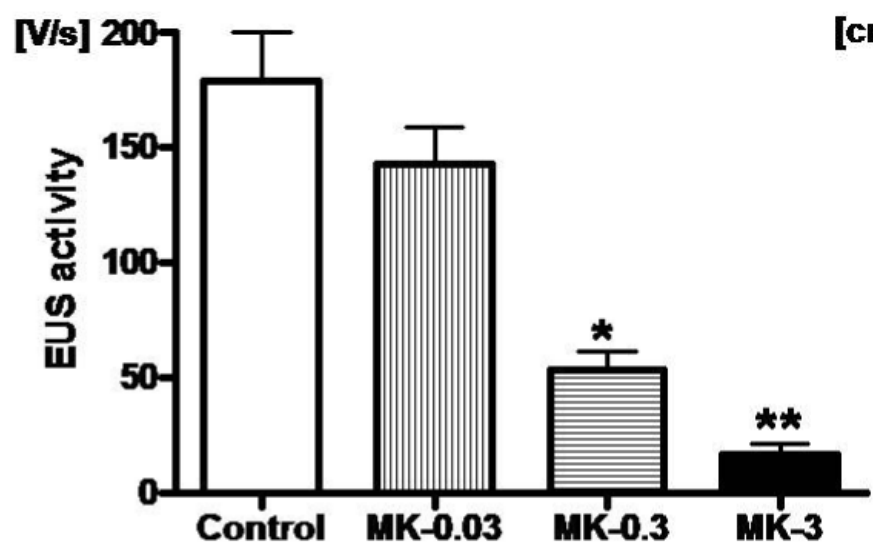

B

$\left.\mathrm{cmH}_{2} \mathrm{O}\right] 200$

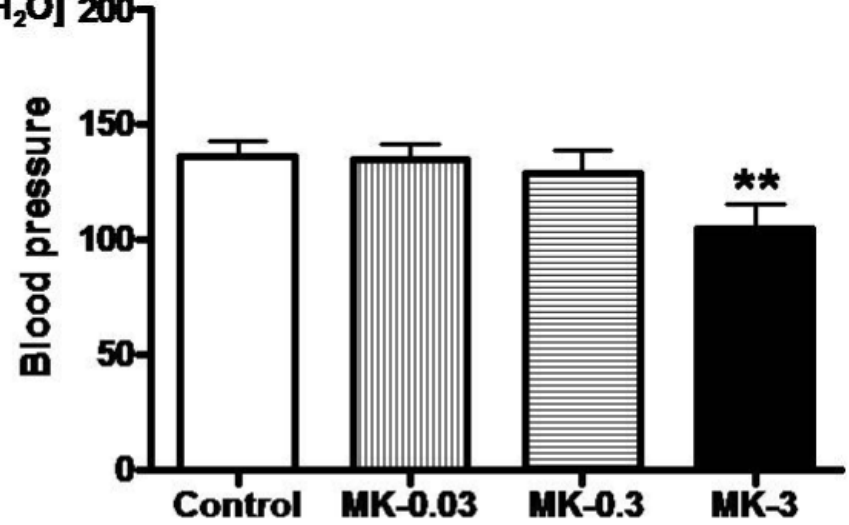

FIGURE 2.

Effects of cumulative application of MK-801, a NMDA glutamate receptor antagonist, on EUS activity and blood pressure. A; higher single doses (0.3 and $3 \mathrm{mg} / \mathrm{kg}$ ) of MK-801 (MK)

significantly decreased the EUS activity during abdominal compression by $70 \%(* \mathrm{P}<0.05)$ and $91 \%(* * \mathrm{P}<0.01)$ compared with pre-drug control, respectively. B; the highest dose $(3 \mathrm{mg} / \mathrm{kg})$ of MK-801 significantly decreased the mean blood pressure compared with control $(* * \mathrm{P}<0.01)$. 
A

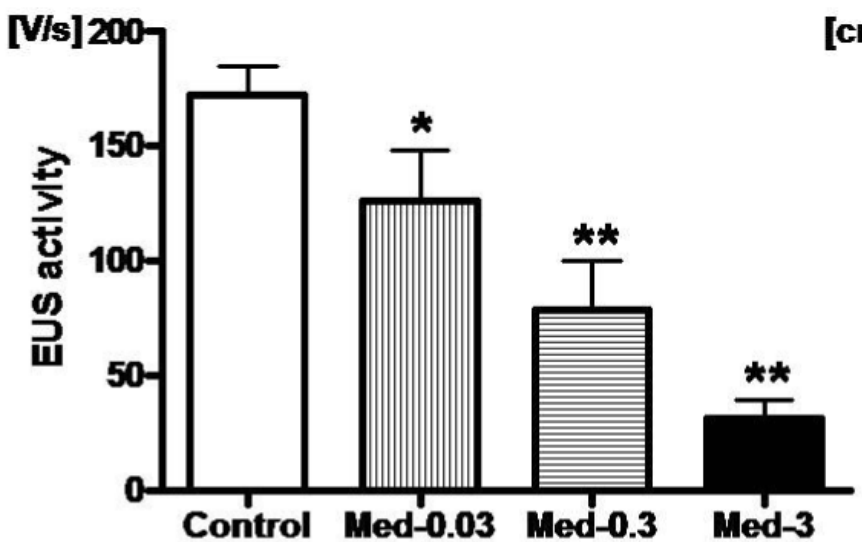

B

$\left[\mathrm{CmH}_{2} \mathrm{O}\right] \mathbf{2 0 0}_{7}$

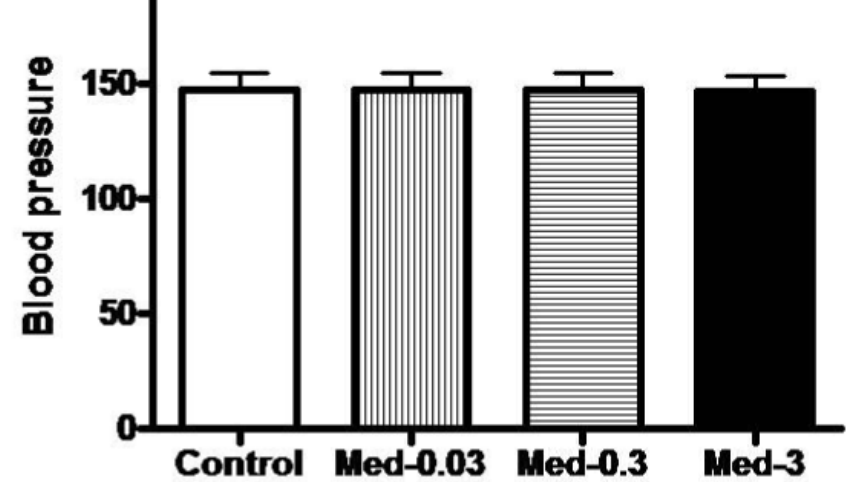

FIGURE 3.

Effects of medetomidine, an $\alpha_{2}$-AR agonist, on EUS activity and blood pressures. A;

Cumulative application of medetomidine (Med; $0.03,0.3$ and $3 \mathrm{mg} / \mathrm{kg}$ ) significantly decreased the EUS activity during abdominal compression dose-dependently by $27 \%(* \mathrm{P}<0.05), 54 \%$ $(* * \mathrm{P}<0.01)$ and $82 \%(* * \mathrm{P}<0.01)$ compared with pre-drug control, respectively. B; Cumulative application of medetomidine did not change the mean blood pressure. 

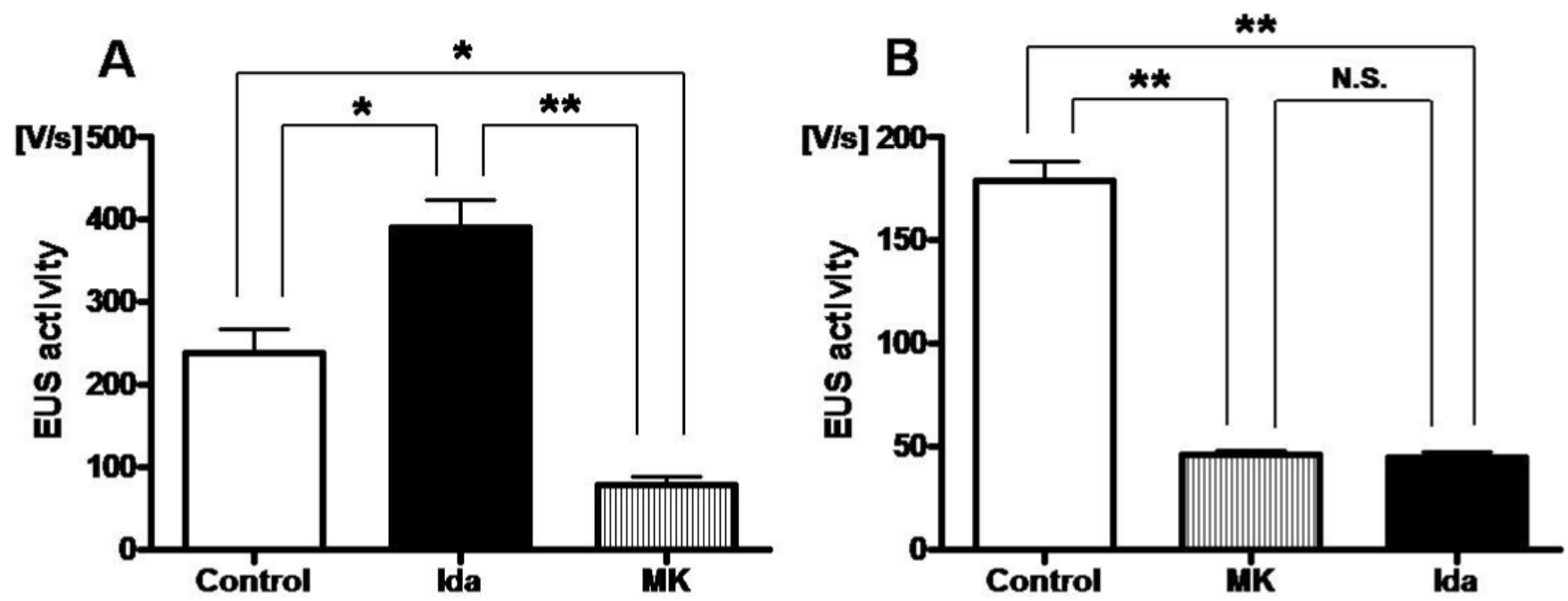

FIGURE 4.

Relationship between the effects of idazoxan, an $\alpha_{2}$-AR antagonist, and MK-801, a NMDA glutamate receptor antagonist, on EUS activity. A; Idazoxan (Ida; $0.3 \mathrm{mg} / \mathrm{kg}$ ) significantly increased the EUS activity during abdominal compression by $64 \%$ compared with pre-drug control $(* \mathrm{P}<0.05)$. The increased EUS activity after idazoxan was then eliminated and reduced to the level lower than control $(* \mathrm{P}<0.05)$ after subsequent application of MK-801 $(\mathrm{MK} ; 1 \mathrm{mg} /$ $\mathrm{kg}$ ). B; MK-801 significantly decreased the EUS activity by $74 \%$ compared with pre-drug control $(* * \mathrm{P}<0.01)$, but the decreased EUS activity by MK-801 was not changed by subsequent application of idazoxan. 

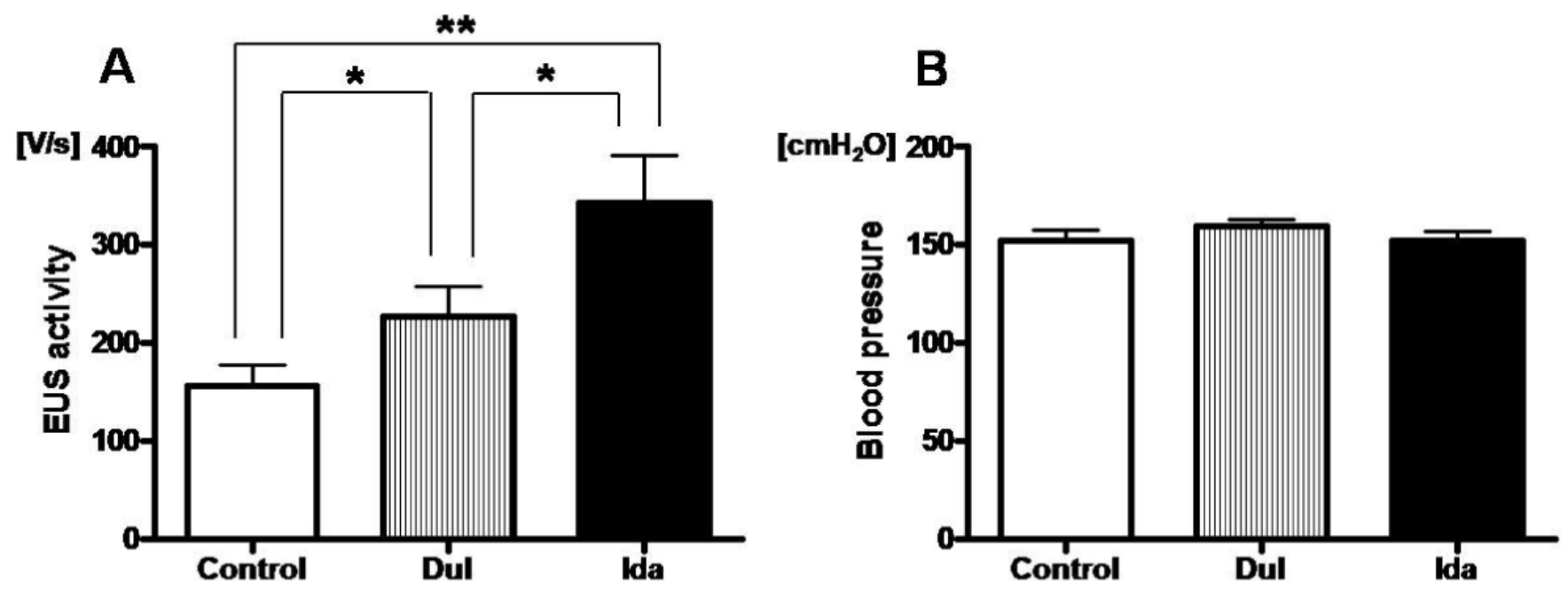

FIGURE 5.

Effects of idazoxan, an $\alpha_{2}$-AR antagonist, in combination with duloxetine, a 5-HT/NE reuptake inhibitor, on EUS activity. A; duloxetine (Dul; $1 \mathrm{mg} / \mathrm{kg}$ ) significantly increased the EUS activity during abdominal compression by $45 \%$ compared with pre-drug control $(* \mathrm{P}<0.05)$, and the increased EUS activity by duloxetine was significantly augmented by idazoxan (Ida; $0.3 \mathrm{mg} / \mathrm{kg})$ by $52 \%$ compared with duloxetine alone $(* \mathrm{P}<0.05)$ or by $120 \%$ compared with preduloxetine control $(* * \mathrm{P}<0.01)$. B; Consecutive application of duroxetine and idazoxan did not change the mean blood pressure. 


\section{Bladder afferent pathway}

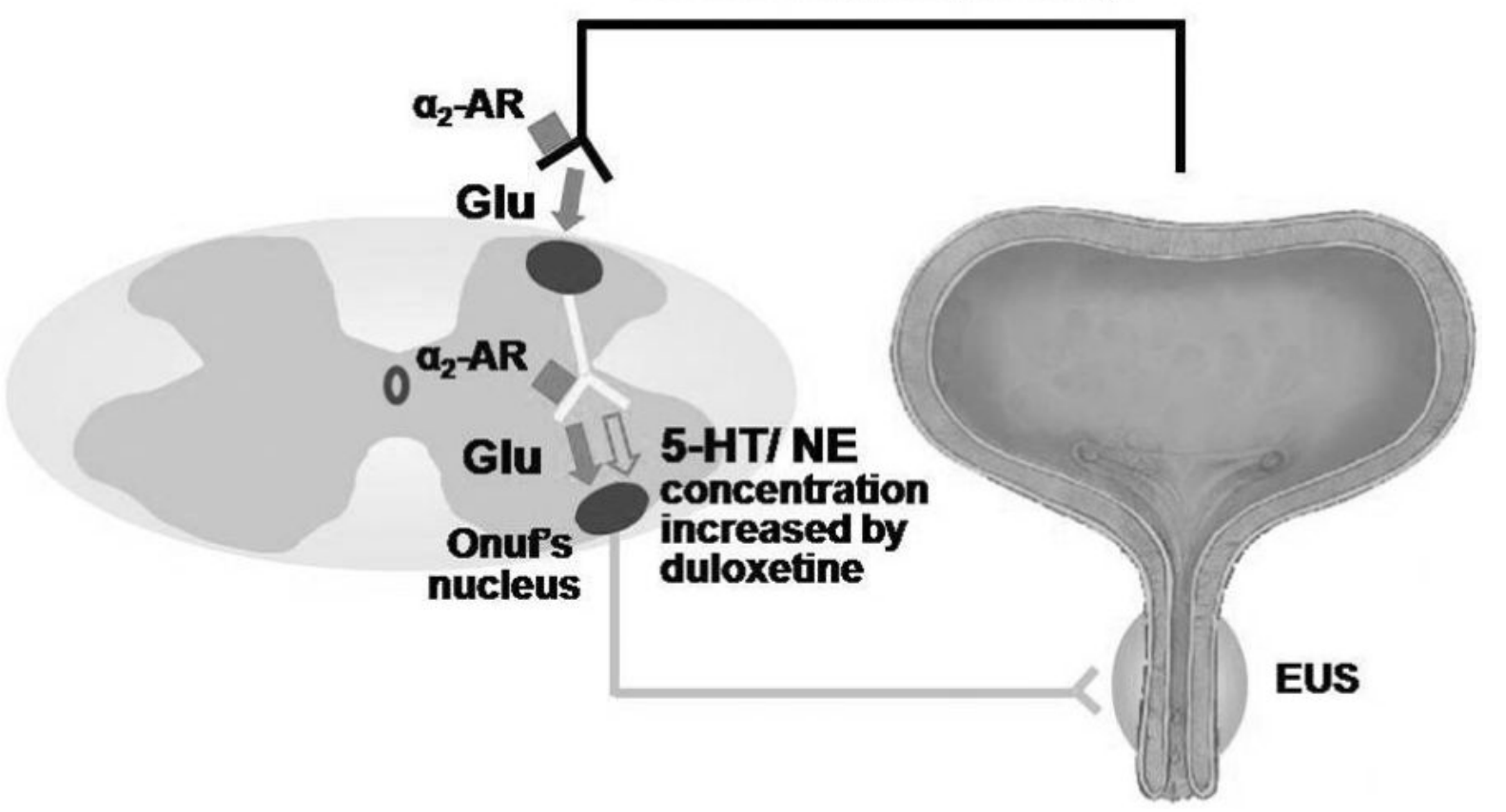

FIGURE 6.

Hypothetical schema of $\alpha_{2}$-adrenoceptor (AR) and glutamatergic (Glu) mechanisms in the control of external urethral sphincter (EUS) continence reflex induced by abdominal compression. Glutamate is the major excitatory neurotransmitter, and $\alpha_{2}$-AR activation suppresses EUS activity probably via $\alpha_{2}$-AR-mediated presynaptic inhibition of glutamate release. In addition, the effects of serotonin (5-HT)/norepinephrine (NE) reuptake inhibitors can be enhanced by $\alpha_{2}$-AR antagonists that suppress $\alpha_{2}$-AR activation induced by increased NE. 